\title{
Accounting
}

\section{Factors affecting the environmental management accounting implementation and the quality of environmental information for making decisions of fishery processing enterprises in Vietnam}

\author{
Thi Minh Hue Le ${ }^{a}$, Lan Anh Dang ${ }^{b^{*}}$ and Thi Hong Le ${ }^{b}$
}

${ }^{a}$ First Author and Corresponding Author. Lecturer, Faculty of Economics and Business Administration, Hong Duc University, Vietnam ${ }^{b}$ Lecturer, Faculty of Economics and Business Administration, Hong Duc University, Vietnam

\begin{tabular}{l}
\hline C H R O N I C L E \\
\hline Article history: \\
Received March 72020 \\
Received in revised format March \\
102020 \\
Accepted May 12020 \\
Available online \\
May 12020 \\
\hline Keywords: \\
Environmental Management \\
Accounting (EMA) \\
Environmental information \\
Information quality \\
Fishery Processing Enterprises \\
(FPEs) in Vietnam
\end{tabular}

\begin{abstract}
Due to increase in global pressures and interest in environmental issues over the past two decades, Environmental Management Accounting (EMA) has been emerged as a new technique in accounting field in order to provide information based on environmental issues for various parties. The environmental accounting information disclosure benefits the decision makers for managing and improving environmental performance. This study aims to assess factors affecting the Environmental Management Accounting Implementation and affecting the Quality of Environmental Information for making decisions of Fishery Processing Enterprises (FPEs) in Vietnam. There are 3 groups of factors including Company's nature and perspective; Government and Stakeholders' Pressure; Methods, tools and regulations for EMA which are examined to learn about their impacts on EMA Implementation and Environmental Data Quality for decision making of FPEs in Vietnam. The result showed that the 3 factors had a causal relationship with EMA Implementation. At the same time, EMA Implementation has the positive impact on Environmental Data quality for decision making of the FPEs in Vietnam. Based on the results of survey and data processing, the authors propose FPEs in Vietnam to increase the effectiveness of methods and tools for EMA, be more responsible for government and stakeholders' pressure, promote managers' perspectives related to environmental issues, and enhance EMA implementation, from which to increase the quality of environmental data for decision making.
\end{abstract}

\section{Introduction}

Vietnam is a strong exporter of fishery, and fishery products are present in 160 countries around the world. Vietnam is currently the $1^{\text {st }}$ country in terms of pangasius market, $2^{\text {nd }}$ country for shrimp market; but for whole fishery products, this country is ranked 3rd, just following China and Norway. The EU is also Vietnam's major fishery export market, with the top import value. With the current development trend of Vietnam's fishery industry, the supply of aquatic products can meet domestic demand and need to be exported to the world market. The value of Vietnam's fishery export is increasing; by 2025 the total export value of the whole fishery industry will reach about 13.473 million USD. In particular, shrimp product is estimated for $63,0 \%$; pangasius is estimated for $17.0 \%$; tuna is estimated for $6.0 \%$; and other fishery is estimated for $5.0 \%$. Table 1 shows the structure of Vietnam's exported fishery products in the period of 2010-2015 and forecast until 2025.

* Corresponding author. Tel.: +84 915086945

E-mail address: danglananh@hdu.edu.vn (A. H. Le) 


\section{Table 1}

Structure of Vietnam's exported fishery products in the period of 2010-2015 and forecast until 2025

\begin{tabular}{llcccccccc}
\hline No & Categories & $\mathbf{2 0 1 0}$ & $\mathbf{2 0 1 5}$ & $\mathbf{2 0 2 0}$ & $\mathbf{2 0 2 1}$ & $\mathbf{2 0 2 2}$ & $\mathbf{2 0 2 3}$ & $\mathbf{2 0 2 4}$ & $\mathbf{2 0 2 5}$ \\
\hline 1 & Shrimp & 2.030 & 2.952 & 5.295 & 5.823 & 6.403 & 7.041 & 7.743 & 8.515 \\
1.1 & Black tiger shrimp & 1.439 & 963 & 1.146 & 1.204 & 1.266 & 1.332 & 1.402 & 1.476 \\
1.2 & Vannamei Shrimp & 415 & 1.742 & 3.707 & 4.166 & 4.673 & 5.234 & 5.855 & 6.541 \\
1.3 & Other shrimp & 253 & 247 & 442 & 453 & 464 & 475 & 486 & 497 \\
2 & Pangasius & 1.425 & 1.565 & 2.064 & 2.100 & 2.135 & 2.167 & 2.198 & 2.227 \\
3 & Tuna & 293 & 455 & 645 & 673 & 701 & 729 & 757 & 786 \\
4 & Squid and octopus & 317 & 429 & 585 & 607 & 629 & 650 & 672 & 694 \\
5 & Other & 1.071 & 1.171 & 1.178 & 1.193 & 1.208 & 1.222 & 1.237 & 1.251 \\
\hline Total & & $\mathbf{5 . 0 1 9}$ & $\mathbf{6 . 5 7 3}$ & $\mathbf{9 . 7 6 8}$ & $\mathbf{1 0 . 3 9 7}$ & $\mathbf{1 1 . 0 7 6}$ & $\mathbf{1 1 . 8 1 1}$ & $\mathbf{1 2 . 6 0 8}$ & $\mathbf{1 3 . 4 7 3}$ \\
\hline & & & & & (Source: Institute of Fishery Economics and Planning, 2016)
\end{tabular}

Regarding the structure of Vietnam's fishery export market by 2025, the US is still the leading fishery import market of Vietnam, accounted for 18,33\%; the next market is the EU (accounted for 11,44\%); Japan (accounted for 11,24\%); China (accounted for 9,57\%); Korea (accounted for 7,67\%); ASEAN (accounted for 6,36\%); Australia (accounted for 2,27\%); and other markets (accounted for 33,13\%). (See Table 2)

Table 2

Structure of Vietnam's exported fishery market in the period of 2010-2016 and forecast to $2025 \quad$ (In million USD)

\begin{tabular}{|c|c|c|c|c|c|c|c|c|c|}
\hline No & Market & 2010 & 2015 & 2020 & 2021 & 2022 & 2023 & 2024 & 2025 \\
\hline 1 & US & 956 & 1.322 & 1.987 & 2.083 & 2.180 & 2.277 & 2.374 & 2.470 \\
\hline 2 & EU & 1.204 & 1.175 & 1.452 & 1.471 & 1.490 & 1.508 & 1.525 & 1.541 \\
\hline 3 & Japan & 894 & 1.043 & 1.323 & 1.361 & 1.399 & 1.437 & 1.476 & 1.514 \\
\hline 4 & China & 246 & 615 & 973 & 1.036 & 1.099 & 1.163 & 1.226 & 1.289 \\
\hline 5 & Korea & 389 & 585 & 813 & 857 & 901 & 945 & 989 & 1.033 \\
\hline 6 & ASEAN & 215 & 499 & 665 & 703 & 741 & 780 & 818 & 857 \\
\hline 7 & Australia & 151 & 179 & 256 & 266 & 276 & 286 & 296 & 306 \\
\hline 8 & Other & 964 & 1.154 & 2.299 & 2.620 & 2.990 & 3.415 & 3.904 & 4.463 \\
\hline \multicolumn{2}{|r|}{ Total } & 5.019 & 6.573 & 9.768 & 10.397 & 11.076 & 11.811 & 12.608 & 13.473 \\
\hline
\end{tabular}

The EU-Vietnam Free Trade Agreement (EVFTA) was signed in 2019 to help Vietnam's fishery industry have a competitive advantage over rivals such as Thailand, China, Indonesia, and India. Right after EVFTA came into effect, 90\% of the Taxes on aquatic products exported to the EU will be reduced to $0 \%$ in 3-4 years (the current import tax rate on the EU is about $14 \%$ ). However, after the application of the "Yellow Card" to Vietnamese fishery products exported to the EU in October 2017, the value of fishery exports to the EU market was strongly impacted. The receipt of the EU "Yellow Card" causes many negative effects directly affecting the export of fishery to EU countries. Vietnam Association of Fishery Exporters and Producers (VASEP) said that by the end of June 2018: the total fishery export to the EU was only US $\$ 584$ million, ranked $4^{\text {th }}$ among the major consumer markets. Vietnam's fishery followed the US which reached 626 million USD, Japan reached 599 million USD and China reached 586 million USD. Meanwhile, the expected supply of aquatic products in 2025 is only 181,76 million tons (aquaculture is estimated for 49,11\%; and fishing production is estimated for 50,89\%). Moreover, Vietnam is a country facing many environmental problems: environmental pollution, environmental degradation, environmental incidents and adverse changes of nature. The National Assembly enacted the Environment Law for the first time in 1993 and the Law on Environmental Protection was amended in 2014. Subsequently, on November $15^{\text {th }}$ 2010, the Law on Environmental Protection Tax was passed. The national strategy for environmental protection to 2020, vision to 2030 of the Government has been developed to redefine the orientations and priorities in environmental protection as well as to limit natural resources over exploitation. In the context of globalization, environmental protection is synonymous with limiting environmental risks, implementing social responsibilities well and ensuring sustainable development of enterprises. Vietnam currently has 520 enterprises processing frozen fishery products with a total freezing capacity of more than 8.000 tons/ day. In which, enterprises with EU codes are more than 300 businesses. Fishery processing activities cause great environmental pollution because the production process generates huge waste streams in the form of liquid, solid and gaseous wastes. In order to effectively manage environmental performance, managers must control the environmental information generated at the fishery processing enterprises (FPEs), control the reduction of waste emissions and environmental issues, focus on addressing the purpose, minimize adverse impacts on the environment. Environmental Management Accounting (EMA) information in the enterprises has important implications for corporate governance, helping managers identify the obligations and also the benefits that the FPEs gain from the environment. From there, the managers will be more proactive in the obligations to the environment to help reduce environmental risks as well as public health risks. Besides, EMA information also helps managers to detect the size and nature of each expense, each content of environmental costs such as repairing, compensation, remedy, cleaning or treating cost; as well as environmental benefits which have not been comprehensively recognized by the FPEs. From which to control or make right environmental 
decisions. Therefore, the authors study "Factors affecting the Environmental Management Accounting (EMA) Implementation and affecting the Quality of Environmental Information for making decisions of Fishery Processing Enterprises (FPEs) in Vietnam" in order to help their managers determine factors affecting their EMA implementation currently, consider to apply EMA in coming time; and identify correct and sufficient environmental information that is responsive to environmental decision making.

\section{Literature Review}

\subsection{Literature Review of Environmental Management Accounting and Environmental Information}

Due to increase global pressures and interest with environmental issues over the past two decades, EMA has been emerged as a new technique in accounting field in order to provide information in regard to environmental issues for various parties. EMA is an important tool can help to reduce environmental impacts and improve environmental performance of organizations, as well as achieve a sustainability. In fact, the issue of adoption, implementation of EMA remains in early stage particularly in developing countries. More interested discussion is given to address environmental impacts by different industries around the world (Li, 2004). Among the most significant contributions is the identification of numerous concepts and techniques related to EMA, such as environmental cost, environmental reports, and types of EMA information, environmental management and environmental performance indicators, monetary information and physical information, environmental information within the formal Management Accounting Information System, cost-benefit analysis, audits of the environmental issues (Frost \& Wilmshurst, 2000). Many governments of developed countries over the world are currently involved or interested in promoting EMA practices (Burritt, 2004; Li, 2004; UNDSD, 2000, 2001). However, EMA has not received any support or attention by government or professional organizations in developing countries so far. In fact, an increasing number of studies related to EMA in various industry sectors and some of small and medium companies are gradually growing up. In addition, it has been increased attention for the role of accounting information systems in providing sufficient information on environmental impacts and activities for various stakeholders. The environmental accounting information disclosure can be benefit to decision makers for managing, auditing and improving environmental performance. (Li, 2004). Meanwhile, Vardon et al. (2018) has studied how the System of Environmental-Economic Accounting (SEEA) can improve environmental information systems and data quality for decision making. The authors used Clarke et al., (2011) measurement to examine the Environmental Information Quality for decision making.

\subsection{Literature Review of Factors affecting Environmental Management Accounting Implementation}

The past literature review shows that many factors significantly contributed in emerging and spreading of EMA concept and practices in several countries around the world; however, in developing countries, the spreading of EMA is still under level comparing with developed countries. The most important drivers include increasing of environmental legislation, governmental initiatives, environmental pressure groups, companies' nature, managers' perspective and failure of the conventional accounting systems in addressing environmental issues. Karimi et al. (2017) analyzed factors affecting the adoption of EMA to provide a conceptual model, from the financial managers and assistants point of view, who are in the oil refining and petrochemical companies. The result showed that resistance to change, lack of standards and methods for gathering and allocation of environmental costs and lack of standards, competitive environment and society culture in dealing with environmental issues are the factors that influence the use of EMA tools. Welford and Gouldson (1993) stated that the environmental legislation development is one of the most important factors that influence the industry behavior in environment field. In addition, increasing the pressures from various stakeholders' groups such as governments, employees, consumers, lenders, shareholders and investors played an important role in emergence of EMA (Gale, 2006; IFAC, 2004). These pressures have impacted organizations' behavior in regard to environmental responsibility and change their management systems including accounting. In this regard, the UNDSD (2000) stated that number of businesses start to review and change their management procedures as response to stakeholders' pressures for more correctly measuring environmental costs and of environmental protection benefits. In recent decades, there are regulations and laws that deal with environmental issues in many countries such as the US, Canada, Japan. As a result, management accounting, thus, has been required more than before to help organizations reduce environmental impacts and the improve environmental performance. Therefore, it is safe to say that increased regulations are forced many organizations for adoption and implementation EMA practices in many countries (Wilmshurst \& Frost, 2001). According to IFAC (2005), several levels of environmental pressures exist such as pressures of supply chain, pressure exerted by various stakeholders on companies to disclose their environmental performance (Schaltegger \& Burritt, 2000); pressures of financing; disclosure requirements of investments policy and investments rating systems (IFAC, 2005); pressure of regulatory control, such as European Union regulations relating to restricts the using of dangerous substances in electronic and electrical equipment sold in European countries (Schaltegger \& Burritt, 2000); pressures of Environmental taxes, for example, emissions fees, landfill fees energy use taxes and carbon taxes, that imposed by governments (IFAC, 2005); pressure of cap and trade, for example Kyoto Protocol which included important aspects on trading and emissions cap (IFAC, 2005). Organizations are facing growing concerns from stakeholders about their environment-related impacts; and those stakeholders need various types of information. For example, company's management requires data about revenues, costs and profits. Community and environment protection agencies need information about the environment-related impacts, whereas the tax authorities, shareholders, and investors are concerned on 
the environmental assets and liabilities. Thus, environmental accounting emerged in order to supply needed information that meets all stakeholders.

Some studies conferred the impact of methods, tools and regulations of EMA on EMA implementation. UNDSD (2000) conferred that using conventional accounting system was not able the firm from accurately identifying upon environmental costs. This is supported by Gale (2006), who sees that traditional management accounting typically does not supply accurate and sufficient information to the management for managing environmental impacts. This is considered another reason push toward development of conventional management accounting practices to include environment-related issues. Moreover, organizations need a big range of expertise in different aspects, such as the management, technique, finance, accounting and environmental for making effective decisions to reduce the environment-related costs, and gain more benefits, as well as the pressures mentioned above (IFAC, 2005). Gray et al. (1993) indicated that, accounting profession and accountants have a lot to contribute with regard to measure and report environmental performance. Furthermore, literature review (Burritt \& Saka, 2006; IFAC, 2004; UNDSD, 2001; Wilmshurst \& Frost, 2001) shows there are some problems and barriers of the traditional accounting practices and systems with regards to environmental issues and related costs and benefits, including: Communications among the other functions and accounting frequently are not well developed. For example, the accountants often are not providing the information that may be most useful for the staff in the environmental or technical departments.

Another aspect of research on EMA implementation is the company's nature and managers' perspective. Roger (1995) conferred that managers who are more knowledgeable about EMA, appreciate the usefulness of EMA information, would have higher demand in using information provided by EMA and they are willing to accept the costs incurred by the application of the EMA. Phan et al. (2017) addressed the comprehensiveness of the EMA of managers and their support were found to influence the use of EMA. Roger (2015) implied that managers in heavy manufacturing companies are generally willing to change and prepare for EMA development under perceived high regulatory, economic, environmental and international pressures. However, the readiness of managers to embrace EMA depends on how soon concerns about regulatory inconsistency at local levels and low environmental awareness among employees can be resolved. Hamzah et al. (2018) examine the association between the Environmental Strategy (ES) and EMA usage, the results indicated that ES positively affects the level of EMA usage and a positive relationship between EMA and the organizational performance. Roger (2011) explored the motivations for EMA use with a view to improving waste and recycling management by local government in the state of New South Wales, Australia. The case studies found 2 main motivations encouraging the development of EMA in local government: first, social structural influences, such as regulatory pressures from different environmental regulatory bodies, environmental expectations from local communities, and pressures from peer councils; second, organizational contextual influences reflecting situational needs in the organizational contexts, such as complex waste operations and service designs, changes and uncertainties in waste and recycling management, and the council's strategic position for waste management.

By contrast, implementation and spread EMA practices still quite limited in the most developing countries including Vietnam with absence of environmental pressures, governments' promotion, and lack forcing legislations. Most companies have poor environmental performance and no sufficient information related to environmental activities in their reports. Burrit (2004) argues that there is an urgent need for further work to identify problems and barriers that face use and spread of EMA practices wide world especially in developing countries in general and in FPEs in Vietnam in particular. It is worth mentioning that intensities and types of pressures on companies with regard to adoption and use EMA may vary significantly among different countries especially between developed and developing countries, as well as, from sector to sector in different business, depended on a company's participation in international markets (IFAC, 2004). This article focused on the most important factors affecting the EMA implementation and the environmental information quality of FPEs in Vietnam by building a model of factors based on the literature review displayed above on EMA implementation and factor affecting environmental information quality. .

\section{Methodology}

\subsection{Research Models and Hypotheses}

In this study, we aim to evaluate the impact of the factors on EMA implementation and environmental information quality for decision making of FPEs in Vietnam. With reference to EMA implementation scale, Environmental information quality for decision making scale adopted by previous studies and the actual conditions of FPEs in Vietnam, the authors selected 34 scales that constitute 4 independent factors:

(1) Company's nature and perspectives (COM) This factor is described by COM1-COM7: Business strategy towards sustainable development, managers determine disclosure of environmental activities is the responsibility of the business, willingness to accept costs for applying environmental management accounting, managers believe that implementing EMA helps to increase competitive advantage for businesses, the company's waste disposal process meets government and local requirements, the manufacturing 
process produces a lot of waste, business production lines of the company have a great impact on the environment (Roger 1995, 2011, 2015; Phan et al., 2017; Roger, 2015, Hamzah et al., 2018)

(2) Government and Stakeholders' Pressure: (PRESS) This factor is described by PRESS1 - PRESS7: Pressure of environmental standards for product characteristics and the company's manufacturing process, Pressure of waste management regulations for the company's production, Pressure of local regulations on environmental pollution, Pressure of regulations on environmental fines/fee, Pressure from investors' expectation for the company to adhere to environmental regulations, Pressure from customers' expectation for the company to adhere to environmental regulations, Pressure from suppliers' expectation for the company to adhere to environmental regulations. (Schaltegger \& Burritt 2000, IFAC 2005, Schaltegger \& Burritt 2000, Martin Bennett \& Peter James 1998)

(3) Methods, tools and regulations for EMA (RES): This factor is described by RES1 -RES4: Connection of the accounting department with the environment department of the company; Qualifications of accountants on environmental management accounting; Application of information technology in accounting work; Methods and regulations for EMA implementation of government (UNDSD 2000; Gale 2006; IFAC, 2005; Gray et al. 1993; Burritt 2004; Burritt \& Saka 2006; IFAC 2004; UNDSD 2001; Wilmshurst \& Frost 2001)

(4) EMA Implementation (EMAI): This factor is described by EMAI1-EMAI10: Using both monetary information and physical information, including environmental information within the formal management Accounting Information System, undertaking formal accounting procedures for a number of specific environmental issues, undertaking cost-benefit analysis to determine the viability of various actions which include the consideration of environmental issues, undertaking audits of the environmental issues impacting on the firm as a result of the firm's activities, reporting environmental information to external stakeholders, using software to track environmental information, developing environmental performance indicators, integrating environmental information into short-term decisions, integrating environmental information into long - term decisions ((Frost and Wilmshurst 2000, authors' analysis)

And 01 dependent factor: (5) Environmental Data Quality for decision making (DATA) factor is described by DATA1-DATA6: Relevance, Accuracy, Timeliness, Accessibility, Interpretability, Coherence (Clarke et al., 2011, Meanwhile, et al., 2018)

The research model is established on the assumptions that factors (1), (2), (3) have direct impact on (4) and (4) has direct impact on (5) of FPEs in Vietnam, as shown in Fig. 1.

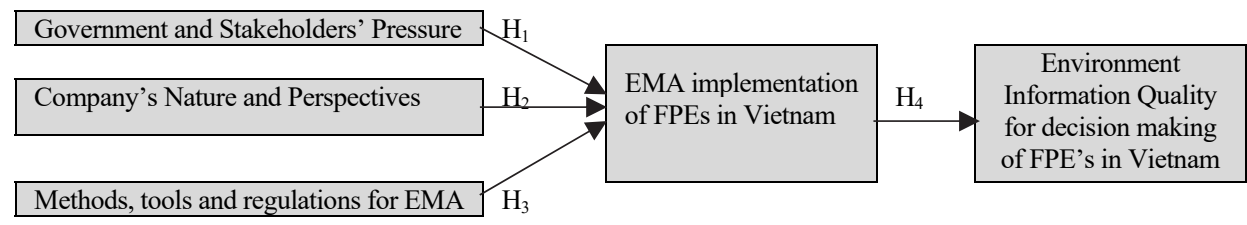

\section{Hypothesis:}

Fig. 1. Research model

Hypothesis H1: Government and Stakeholders' Pressure (PRESS) positively affects the EMA Implementation (EMAI) of the FPEs in Vietnam.

Hypothesis $\mathbf{H}_{2}$ : Company's nature and perspectives (COM) positively affects the EMA Implementation (EMAI) of the FPEs in Vietnam.

Hypothesis $\mathbf{H}_{3}$ : Methods, tools and regulations for EMA (RES) positively affects the EMA Implementation (EMAI) of the FPEs in Vietnam.

Hypothesis H4: EMA Implementation (EMAI) of the FPEs in Vietnam positively affects Environmental Data quality (DATA) for decision making of the FPEs in Vietnam.

\subsection{Research Method}

Research methodology was conducted through 2 steps: Qualitative research and quantitative research.

Qualitative research was conducted with a sample of 20 managers at the FPEs to explore Factors perceiving the EMAI and examining the Quality of Environmental Information for making decisions of FPEs in Vietnam. Qualitative research results help the authors establish quantitative measurement tools. 
Quantitative research was conducted through 2 phases.

In phase 1, the authors experimented on a small group to detect errors in the questionnaire.

In phase 2 , the authors conducted a revised questionnaire.

The survey was conducted in December 2019. According to the study of Hair et al. (1998), if the sample size is around 100, the loading factor standard must be greater than 0.5. Bollen (1986) proposed the ratio of 5 observations per estimated parameter in the multivariate analysis. In the research, there are 34 variable observations, so the minimum sample size should be equal to $34 \times 5=$ 170 samples. The study has a sample size of 350 managers of FPEs in Vietnam, which can meet the requirements and be generalizable, representative of the total study; The total number of valid questionnaires collected and processed was 300 questionnaires. Hair et al. (1998) also recommends that study subjects were asked to answer questions on a 5-level Likert scale (from 1 totally disagree to 5 totally agree). Questionnaires answered by respondents were the main tool for collecting data. The author performs Exploratory Factor Analysis (EFA), Confirmatory Factor Analysis (CFA), and Linear Structural Modeling (SEM) using SPSS.20 software in combination with AMOS.20. Accreditation was done through the following steps:

- Preliminary evaluation on the measurement scale and reliability of variables by Cronbach's Alpha and Factor Loading by the Exploratory Factor Analysis (EFA).

- The CFA method was used to test critical models by examining univariate, multivariate, convergent and discriminated values of concepts.

- From the CFA results, to construct and validate the fit of the research model through the SEM model, to assess the impact of independent variables on the dependent variable.

- Measurement scale of research concepts: Including 34 observed variables (Corresponding to 4 independent factor groups and 1 group of dependent factors)

- Sample survey statistics: The number of questionnaires sent was 350; 300 valid votes were used for this analysis. The survey subjects were managers of all levels of the FPEs in Vietnam

\section{Results}

\subsection{Descriptive Statistics}

The study has a sample size of 300 managers, resulting in a total of 350 valid survey questionnaires collected and processed. Demographic information of the observed sample is presented in Table 3.

Table 3

Description of demographic characteristics of the surveyed sample

\begin{tabular}{|c|c|c|c|c|c|c|c|}
\hline \multicolumn{2}{|c|}{ Content } & Frequency & Percent & Content & & Frequency & Percen \\
\hline \multirow{3}{*}{ Gender } & Male & 197 & 66 & \multirow{3}{*}{ Education } & Bachelor degree & 195 & 65 \\
\hline & Female & 103 & 34 & & Post graduate degree & 105 & 35 \\
\hline & Total & 300 & 100 & & Total & 300 & 100 \\
\hline \multirow{4}{*}{ Age } & $25-35$ years & 98 & 33 & \multirow{3}{*}{ Company region } & The North of & 74 & 14.2 \\
\hline & $35-50$ years & 156 & 52 & & The South of & 305 & 58.7 \\
\hline & $>50$ & 46 & 15 & & The Central of & 141 & 27.1 \\
\hline & Total & 300 & 100 & Total & & 520 & 100 \\
\hline \multirow{5}{*}{ Department } & General & 80 & 26.7 & \multirow{5}{*}{$\begin{array}{l}\text { Types of fishery } \\
\text { products }\end{array}$} & Frozen & 381 & 73.3 \\
\hline & Accounting & 102 & 34 & & Dry products & 108 & 20.7 \\
\hline & Environment & 83 & 27.6 & & Canned food & 17 & 3.26 \\
\hline & Other & 35 & 11.7 & & Fish sauce & 12 & 2.3 \\
\hline & Total & 300 & 100 & & Shrimp chips & 2 & 3.8 \\
\hline \multirow{5}{*}{ Ownership } & State-owned & 91 & 17.5 & Total & & 520 & 100 \\
\hline & Joint stock & 159 & 30.64 & & \multirow{5}{*}{\multicolumn{3}{|c|}{ (Source: The author's data analvsis) }} \\
\hline & Private & 248 & 47.7 & & & & \\
\hline & Joint venture & 9 & 1.73 & & & & \\
\hline & Enterprises & 13 & 2.5 & & & & \\
\hline \multicolumn{2}{|l|}{ Total } & 520 & 100 & & & & \\
\hline
\end{tabular}

\subsection{Scale reliability test results and exploratory factor analysis}

The total number of valid questionnaires collected was 300 samples. The authors used SPSS.20 software to process 34 variables, the 2 variables including Data 6 (Coherence), COM6 (The manufacturing process produces a lot of waste) were eliminated because of their Corrected Item - Total Correlations are smaller than 0.3 . The 32 remaining variables were retained ( 27 independent variables and 5 dependent variables). 


\subsection{Analysis of Exploratory Factor}

According to Anderson and Gerbing (1988), Principal Axis Factoring was used with Promax rotation and factor loading coefficients $\geq 0.5$ to incorporate remaining variables into Exploratory Factor Analysis (EFA) model for the purposes of scale validation. We have the resultant KMO coefficient $=0,925>0,5$; Bartlett's Test statistics are 5826,984 with significance level of $0.000<0,05$; Cumulative of Variance is $72.072 \%(>50 \%)$. This proves that the analytical data is perfectly relevant. Thus, all factor loading coefficients are greater than 0,5 ; explained variance is greater than $50 \%$, the remaining 32 observed variables are grouped exactly as the original scale.

\section{Table 4}

KMO and Bartlett's Test

Kaiser-Meyer-Olkin Measure of Sampling Adequacy.

Bartlett's Test of Sphericity

(Source: The author's data analysis)

It is shown in the EFA results the following factors:

Factor 1: includes the observed variables PREE1-PRESS7 and is named "Government and Stakeholders' Pressure" (PRESS).

Factor 2: includes observed variables COM1-COM7 (except COM6) and is named "Company's nature and perspectives" (COM). Factor 3: includes observed variables RES1-RES4 and is named "Methods, tools and regulations for EMA" (RES).

Factor 4: includes observed variables EMAI1-EMAI10 and is named "EMA Implementation" (EMAI):).

Factor 5: includes observed variables DATA1-DATA6 (except DATA6) and is named "Environmental Data Quality for decision making" (DATA).

After EFA exploratory analysis, it can be seen that the model has no difference from the research model and no observed variable is excluded from the study variables. There is no new factor group as Table 5:

\section{Table 5}

Exploratory Factor Analysis Matrix

\begin{tabular}{|c|c|c|c|c|c|}
\hline & \multicolumn{5}{|c|}{ Factor } \\
\hline & 1 & 2 & 3 & 4 & 5 \\
\hline EMAI10 & .923 & & & & \\
\hline EMAI3 & .834 & & & & \\
\hline EMAI6 & .807 & & & & \\
\hline EMAI5 & .763 & & & & \\
\hline EMAI4 & .700 & & & & \\
\hline EMAI1 & .688 & & & & \\
\hline EMAI8 & .664 & & & & \\
\hline EMAI7 & .664 & & & & \\
\hline EMAI9 & .632 & & & & \\
\hline EMAI2 & .630 & & & & \\
\hline PRESS3 & & .906 & & & \\
\hline PRESS7 & & .864 & & & \\
\hline PRESS5 & & .862 & & & \\
\hline PRESS2 & & .844 & & & \\
\hline PRESS4 & & .828 & & & \\
\hline PRESS6 & & .781 & & & \\
\hline PRESS1 & & .719 & & & \\
\hline COM3 & & & .810 & & \\
\hline COM2 & & & .683 & & \\
\hline COM7 & & & .673 & & \\
\hline COM4 & & & .640 & & \\
\hline COM5 & & & .562 & & \\
\hline COM1 & & & .516 & & \\
\hline RES2 & & & & .846 & \\
\hline RES3 & & & & .774 & \\
\hline RES4 & & & & .658 & \\
\hline RES1 & & & & .615 & \\
\hline Data4 & & & & & .749 \\
\hline Data2 & & & & & .614 \\
\hline Data5 & & & & & .600 \\
\hline Data3 & & & & & .591 \\
\hline Data1 & & & & & .528 \\
\hline
\end{tabular}




\subsection{Analysis of Confirmatory Factor}

The critical model of research concepts is shown in Fig. 2. The critical model is a model of established factors that are freely interrelated. $\mathrm{CFI}=0.923$, TLI $=0.915$ are all greater than 0.9 (Bentler \& Bonelt, 1980) and RMSEA $=0.056<0.8($ Steiger, 1990). The factor weights of each observed variable are greater than 0.5 , so the model can be considered convergent (Fig. 2 ).

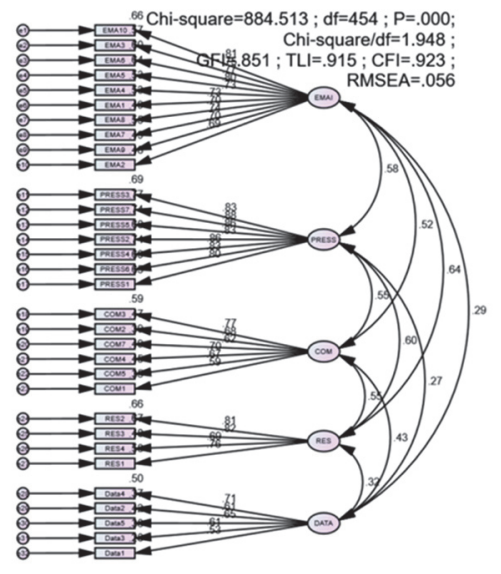

Fig. 2. CFA analysis results for the critical model

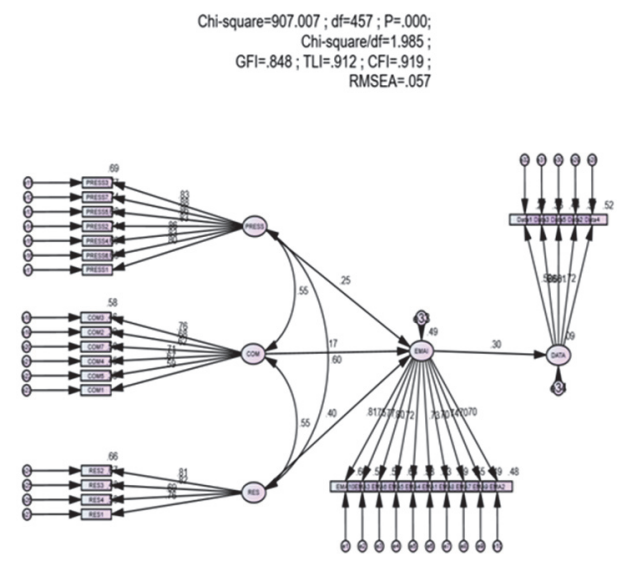

Fig. 3. Standardized Structural Equation Modeling (SEM) (Source: The author's data analysis) Results of the analysis showed that: Correlation coefficients were less than 1, covariance testing and correlation between pairs of variables were statistically significant ( $p<0.05$ value, Table 6$)$. This implies that the factors in the model can be distinguished

Table 6

Computable Reliability Coefficients and Variance of Factors in the Model

\begin{tabular}{|c|c|c|c|c|c|c|}
\hline Factors & & & Estimate & S.E. & C.R. & $\mathbf{P}$ \\
\hline EMA10 & $\leftarrow$ & EMAI & 1 & & & \\
\hline EMA3 & $\leftarrow$ & EMAI & 0.935 & 0.064 & 14.658 & $* * *$ \\
\hline EMA6 & $\leftarrow$ & EMAI & 0.933 & 0.061 & 15.183 & $* * *$ \\
\hline EMA5 & $\leftarrow$ & EMAI & 0.864 & 0.054 & 16.004 & $* * *$ \\
\hline EMA4 & $\leftarrow$ & EMAI & 0.81 & 0.058 & 13.942 & $* * *$ \\
\hline EMA1 & $\leftarrow$ & EMAI & 0.886 & 0.063 & 14 & $* * *$ \\
\hline EMA8 & $\leftarrow$ & EMAI & 0.827 & 0.063 & 13.23 & $* * *$ \\
\hline EMA7 & $\leftarrow$ & EMAI & 0.859 & 0.06 & 14.412 & $* * *$ \\
\hline EMA9 & $\leftarrow$ & EMAI & 0.873 & 0.065 & 13.344 & $* * *$ \\
\hline EMA2 & $\leftarrow$ & EMAI & 0.944 & 0.072 & 13.169 & $* * *$ \\
\hline PRESS3 & $\leftarrow$ & PRESS & 1 & & & \\
\hline PRESS7 & $\leftarrow$ & PRESS & 0.998 & 0.052 & 19.055 & $* * *$ \\
\hline PRESS5 & $\leftarrow$ & PRESS & 0.947 & 0.051 & 18.488 & $* * *$ \\
\hline PRESS2 & $\leftarrow$ & PRESS & 0.954 & 0.055 & 17.347 & $* * *$ \\
\hline PRESS4 & $\leftarrow$ & PRESS & 0.964 & 0.052 & 18.549 & $\overline{* * *}$ \\
\hline PRESS6 & $\leftarrow$ & PRESS & 0.955 & 0.055 & 17.414 & $* * *$ \\
\hline PRESS1 & $\leftarrow$ & PRESS & 0.896 & 0.054 & 16.664 & $* * *$ \\
\hline COM3 & $\leftarrow$ & $\mathrm{COM}$ & 1 & & & \\
\hline COM2 & $\leftarrow$ & COM & 0.756 & 0.067 & 11.318 & $* * *$ \\
\hline COM7 & $\leftarrow$ & COM & 0.795 & 0.077 & 10.281 & $* * *$ \\
\hline COM4 & $\leftarrow$ & COM & 0.812 & 0.07 & 11.67 & $* * *$ \\
\hline COM5 & $\leftarrow$ & COM & 0.894 & 0.08 & 11.122 & $* * *$ \\
\hline COM1 & $\leftarrow$ & COM & 0.759 & 0.078 & 9.758 & $* * *$ \\
\hline RES2 & $\leftarrow$ & RES & 1 & & & \\
\hline RES3 & $\leftarrow$ & RES & 0.96 & 0.064 & 14.94 & $* * *$ \\
\hline RES4 & $\leftarrow$ & RES & 0.738 & 0.06 & 12.278 & $* * *$ \\
\hline RES1 & $\leftarrow$ & RES & 0.968 & 0.07 & 13.806 & $* * *$ \\
\hline Data4 & $\leftarrow$ & DATA & 1 & & & \\
\hline Data2 & $\leftarrow$ & DATA & 0.695 & 0.08 & 8.659 & $* * *$ \\
\hline Data5 & $\leftarrow$ & DATA & 1.033 & 0.114 & 9.085 & $* * *$ \\
\hline Data3 & $\leftarrow$ & DATA & 0.726 & 0.084 & 8.687 & $* * *$ \\
\hline Data1 & $\leftarrow$ & DATA & 0.526 & 0.068 & 7.697 & $* * *$ \\
\hline
\end{tabular}


The study uses the SEM to assess the relevance of the research model and test the relationships in the initial model. The results of the SEM analysis of the model with $\mathrm{df}=457$, Chi-square $=907.007$ with $\mathrm{p}$-value $=0.000<0.05$, Chi-square $/ \mathrm{df}=1.985<3$, $\mathrm{CFI}=0.919, \mathrm{TLI}=0,912$; RMSEA $=0.57<0.8$ should confirm that the pattern consistent with market data (Fig. 3.).

The SEM result shows that the relationship between Environmental Management Accounting Implementation (EMAI) and Environmental Data quality for decision making is acceptable $(\mathrm{p}<0.05)$.

Hypothesis $\mathbf{H}_{\mathbf{1}}$ is accepted (value of $\mathrm{p}<0.05$ ), in which the Government and Stakeholders' Pressure (PRESS) strongly affects the Environmental Management Accounting Implementation (EMAI) of the FPEs in Vietnam. This result is also consistent with the actual conditions of the companies.

Hypothesis $\mathbf{H}_{2}$ is accepted (value of $\mathrm{p}<0.05$ ), in which the Company's nature and perspectives (COM) strongly affects the Environmental Management Accounting Implementation (EMAI) of the FPEs in Vietnam. This result is also consistent with the actual conditions of the companies.

Hypothesis $\mathbf{H}_{3}$ is accepted (value of $\mathrm{p}<0.05$ ), in which the Methods, tools and regulations for EMA (RES) strongly affects the Environmental Management Accounting Implementation (EMAI) of the FPEs in Vietnam. This result is also consistent with the actual conditions of the companies.

Hypothesis $\mathbf{H}_{4}$ is accepted (value of $\mathrm{p}<0.05$ ), in which the Environmental Management Accounting Implementation (EMAI) strongly affects Environmental Data quality (DATA) for decision making of the FPEs in Vietnam. This result is also consistent with the actual conditions of the companies.

Table 7

Coefficients of regression model SEM and test results of the model's hypotheses

\begin{tabular}{llllllll}
\hline & Factors & & Standard Estimate & S.E. & C.R. & P & Note \\
\hline EMAI & $\leftarrow$ & PRESS & 0.210 & 0.057 & 3.676 & Accepted \\
EMAI & $\leftarrow$ & COM & 0.182 & 0.073 & 2.500 & .012 & Accepted \\
EMAI & $\leftarrow$ & RES & 0.347 & 0.065 & 5.361 & $* * *$ & Accepted \\
DATA & $\leftarrow$ & EMAI & 0.333 & 0.076 & 4.371 & *** & Accepted \\
\hline
\end{tabular}

Results of the causal relationship between the components in the research model in Table 5 with $p<0.05$ confirmed that the factors including Government and Related Party Pressure (PRESS), Company Characteristics (COM), Methods, tools and regulations for EMA (RES) have causal relationships with Environmental Management Accounting Implementation (EMAI). At the same time, Environmental Management Accounting Implementation (EMAI) has the positive impact on Environmental Data quality (DATA) for decision making of the FPEs in Vietnam. In which, methods, tools and regulations for EMA Implementation (RES) factor has the biggest impact on Environmental Management Accounting Implementation (EMAI) of the FPEs in Vietnam, following by Government and Related Party Pressure (PRESS) and then Company's nature and perspectives (COM) has less effect; and the Environmental Management Accounting Implementation (EMAI) strongly affects Environmental Data quality for decision making (DATA) of the FPEs in Vietnam.

\section{Discussion}

Based on the results of survey and data processing, the authors propose that, to enhance the environmental data quality for decision making, the FPEs need to enhance all variables of their company's perspective, the stakeholders (including government, investors, customers, and suppliers) need to increase their pressure on environmental issues to the companies; the company also needs to increase the effectiveness of methods and tools for EMA Implementation and the government should issue more regulations on EMA implementation. Some particular solutions for FPEs are following:

\subsection{Increasing the effectiveness of methods and tools for EMA}

The government should issue more regulations on EMA implementation and the FPEs should increase the effectiveness of methods and tools for EMA Implementation. Most of the environmental regulations for fishery operations are complied with by the FPEs in Vietnam, but the environmental information provided from the accounting perspective is very sketchy, without separating costs and turnover from the environment. The reason is that Vietnam does not have any regulations and guidelines for implementing the EMA. The fact shows that, at the FPEs, they always have to take remedies, restorations and environmental 
protection due to the impact of the aquaculture and processing fishery, to ensure the legal requirements and meet their own development. Therefore, when the accounting law has provisions and efficient regulations, the FPEs will apply it more smoothly in all aspects of recording information, presenting reports and providing clear environmental information.

\subsection{Being more responsible for government and stakeholders' pressure}

The FPEs need to be responsible for disclosing the risks that businesses may cause and the solutions that enterprises take to their related parties. Stakeholders outside the enterprise often need information but at different levels.

- The Government is interested in the environmental protection issue of FPEs as it significantly affects the national environmental quality. Accounting information of businesses plays an important role in providing financial information related to environmental issues for fishery management. The EMA information has an important meaning in making statistics on environmental protection measures that enterprises have announced and the results of implementation, with a basis for making environmental policies.

- Investors, customers and suppliers offer interest and benefit to the FPEs, their benefits depend on the FPEs' business results. If there are environmental risks, it will significantly affect the interests of investors, customers and suppliers. Therefore, the parties need to increase their desire on environmental issues to the companies

\subsection{Promoting managers' perspectives related to environmental issues}

In order to successfully apply the EMA, the first requirement needs to have the support and approval of the top management and to give the managers the perspectives of building business strategy towards sustainable development. In addition, the administrators should determine disclosure of environmental activities is the responsibility of the business; be willing to accept costs for applying environmental management accounting. Moreover, they must believe that implementing accounting management environment helps to increase competitive advantage for businesses; the company's waste disposal process meets government and local requirements; and the business production lines of the company have a great impact on the environment.

\subsection{Enhancing EMA implementation}

The FPEs should consider the EMA implementation as an important strategy. They need to use both monetary information and physical information, trace environmental information by detailed accounts, determine environmental costs by modern method, estimate environmental costs, estimate environmental cost report, and develop environmental performance indicators, use software to track environmental information, integrate environmental information into short-term decisions, and integrate environmental information into long-term decisions. From which, to enhance environmental data for decision making.

\section{Conclusion}

Results of the causal relationship between the components in the research model confirmed that the factors including The stakeholders' Pressure (PRESS); Company's nature and perspective (COM); Methods, tools and regulations for EMA (RES) have maintained a causal relationship with Environmental Management Accounting Implementation (EMAI). At the same time, Environmental Management Accounting Implementation (EMAI) has a positive impact on Environmental Data Quality (DATA) for decision making of the FPEs in Vietnam. Based on the results of survey and data processing, the authors propose FPEs in Vietnam to increase the effectiveness of methods and tools for EMA, be more responsible for government and stakeholders' pressure, promoting managers' perspectives related to environmental issues, and enhance EMA implementation, from which to increase quality of environmental data for decision making. The limitation of this study is that it is only implemented at FPEs in Vietnam, an industry with many differences compared to other areas. Therefore, the research results are somewhat different from other industries in the locality and in the country, so the generalizability is not high. Therefore, there should be extensive research on the scope of other fields. The authors hope that further research will address the limitations of this research.

\section{Acknowledgement}

The authors would like to thank the anonymous referees for constructive comments on earlier version of this paper. 
Anderson, J. C., \& Gerbing, D. W. (1988). Structural equation modeling in practice: A review and recommended two-step approach. Psychological Bulletin, 103(3), 411. https://doi.org/10.1037/0033-2909.103.3.411.

Bentler, P. M., \& Bonett, D. G. (1980). Significance tests and goodness of fit in the analysis of covariance structures. Psychological Bulletin, 88(3), 588. DOI: 10.1037/0033-2909.88.3.588

Bollen, K. A. (1986). Sample size and Bentler and Bonett's nonnormed fit index. Psychometrika, 51(3), 375-377. https://doi.org/10.1007/BF02294061

Burritt, R. L. (2004). Environmental management accounting: Roadblocks on the way to the green and pleasant land. Business Strategy and the Environment, 13, 13-32.

Burritt, R. L., \& Saka, C. (2006). Environmental management accounting applications and eco-efficiency: case studies from Japan. Journal of Cleaner Production, 14(14), 1262-1275.

Clarke, N., Fischer, R., de Vries, W., Lundin, L., Papale, D., Vesala, T., Merilä, P., Matteucci, G., Mirtl, M., Simpson, D., Paoletti, E., (2011). Availability, accessibility, quality and comparability of monitoring data for European forests for use in air pollution and climate change science. iForest 4, 162-166. [online 2011-08-11] URL:http://www.sisef.it/iforest/show.php?id=582 (Accessed 6 February 2018)

Gale, R. (2006). Environmental management accounting as a reflexive modernization strategy in cleaner production. Journal of Cleaner Production, 14(14), 1228-1236.

Gray, R., Bebbington, J., \& Walters, D. (1993). Accounting for the Environment. Markus Wiener Pub.

Hair, J. F., Black, W. C., Babin, B. J., Anderson, R. E., \& Tatham, R. L. (1998). Multivariate data analysis. Upper Saddle River, NJ: Prentice Hall

IFAC. (2004). International Guidelines on Environmental Management Accounting (EMA). New York: International Federation of Accountants (IFAC).

IFAC. (2005). International Guidelines on Environmental Management Accounting (EMA) New York: International Federation of Accountants (IFAC).

Institute of Fishery Economics and Planning. (2016). Structure of Vietnam's exported fishery products in the period of 20102015 and forecast until 2025.

Institute of Fishery Economy and Planning. (2016). Structure of Vietnam's exported fishery market in the period of 2010-2016 and forecast to 2025 .

Karimi, Z., Dastgir, M., \& Saleh, M. A. (2017). Analysis of factors affecting the adoption and use of environmental management accounting to provide a conceptual model. International Journal of Economics and Financial Issues, 7(3), 555-560.

Li, X. (2004). Theory and practice of environmental management accounting. International Journal of Technology Management \& Sustainable Development, 3(1), 47-57.

Phan, T.N., Baird, K., \& Su, S. (2017). The use and effectiveness of environmental management accounting, Australasian Journal of Environmental Management, 24(2), 1-20.

Roger Leonard Burritt (2015). The potential for environmental management accounting development in China. Journal of Accounting \& Organizational Change, 11(3), 406-428.

Roger Leonard Burritt (2011), Environmental Management Accounting in Local Government: A Case of Waste Management, Accounting Auditing \& Accountability Journal, 24(January), 93-128.

Schaltegger, S., \& Burritt, R. L. (2000). Contemporary environmental accounting: issues, concepts, and practice. Sheffield: Greenleaf Publishing.

Steiger, J. H. (1990). Structural model evaluation and modification: An interval estimation approach. Multivariate Behavioral Research, 25(2), 173-180.

UNDSD. (2000). Improving Governments' Role In the Promotion of Environmental Managerial accounting New York: United Nation.

UNDSD. (2001). Environmental management accounting: procedures and principals. New York: United Nation Division for sustainable Development: Expert Working Group.

Vardon, M., Castaneda, J. P., Nagy, M., \& Schenau, S. (2018). How the System of Environmental-Economic Accounting can improve environmental information systems and data quality for decision making. Environmental science \& policy, 89, 8392

Welford, R., \& Gouldson, A. (1993). Environmental management and business strategy: London Pitman.

Wilmshurst, T. D., \& Frost, G. R. (2001). The role of accounting and the accountant in the environmental management system. Business Strategy and the Environment, 10(3). 135. 
(C) 2020 by the authors; licensee Growing Science, Canada. This is an open access article distributed under the terms and conditions of the Creative Commons Attribution (CC-BY) license (http://creativecommons.org/licenses/by/4.0/). 